\title{
Deflationary metaphysics and ordinary language
}

\author{
Tim Button 1
}

Received: 4 September 2015 / Accepted: 29 August 2016 / Published online: 13 September 2016 (C) The Author(s) 2016. This article is published with open access at Springerlink.com

\begin{abstract}
Amie Thomasson and Eli Hirsch have both attempted to deflate metaphysics, by combining Carnapian ideas with an appeal to ordinary language. My main aim in this paper is to critique such deflationary appeals to ordinary language. Focussing on Thomasson, I draw two very general conclusions. First: ordinary language is a wildly complicated phenomenon. Its implicit ontological commitments can only be tackled by invoking a context principle; but this will mean that ordinary language ontology is not a trivial enterprise. Second: ordinary language often points in different directions simultaneously, so that a wide variety of existence questions cannot be deflated merely by appealing to ordinary language.
\end{abstract}

Keywords Deflationary metaphysics · Ordinary language · Easy ontology · Metaontology · Metametaphysics · Existence questions · Amie Thomasson · Eli Hirsch · Neo-Carnapian metaphysics · The Context Principle · Mereology

\section{Thomasson's easy ontology}

Thomasson wants to deflate existence questions. She attempts to do so, not by dismissing them as nonsensical, but by providing them with easy answers. I shall begin by outlining some of Thomasson's model questions and answers. ${ }^{1}$

\footnotetext{
1 Thomasson (2009b, pp. 8-12, 2013, pp. 1025-1027, 2015, pp. 37, 102-103, 106-107, 129-153, 258, 2016, Sect. 1, forthcoming, Sect. 1). Thomasson, of course, notes that plenty of existence questions require serious empirical work, e.g. 'are there faster-than-light neutrinos?' However, such questions are not the concern of this paper. I shall not repeat this caveat in what follows, but it holds throughout.

$凶$ Tim Button

button@cantab.net

1 University of Cambridge, Cambridge, UK
} 
Are there properties? The answer is easy. Just consider the following argument:

(1p) that rug is red

(2p) that rug has the property of being red

(3p) there are properties

Here, (1p) is supposed to be given to us fairly directly, (2p) is supposed to follow from $(1 \mathrm{p})$, and then $(3 \mathrm{p})$ from $(2 \mathrm{p})$.

Are there propositions? The answer is as easy as before:

(1t) Tillman is a bulldog

(2t) the proposition that Tillman is a bulldog is true

(3t) there are propositions

Are there numbers? Again, the answer is easy:

(1n) there are four bagels

(2n) the number of bagels is four

(3n) there are numbers

Are there events? Obviously:

(1e) she was born on Monday

(2e) her birth—an event-occurred on Monday

(3e) there are events

Such easy-arguments can be multiplied, but the idea is clear enough. We start by posing some existence question. Thomasson offers an easy-argument in reply. And so Thomasson's easy ontology aims to suck the life out of debating existence questions.

What are the options, if we want to resist the conclusion of these easy-arguments? Indeed: what are the options, if we just want to say that easy-arguments are too easy?

It seems futile to deny the inputs, i.e. the various (1)s. Even if Tillman is not a bulldog, but rather a truly enormous pug, essentially the same argument as (1t)-(3t) will go through. Indeed, to block any possible input to Thomasson's easy-argument for the existence of propositions, we would have to abandon the entire practice of making assertions. And that is hardly a live option.

So, if we want to disagree with Thomasson's conclusions or methods, we will have to contest the inferential steps in her easy-arguments. But Thomasson thinks that this is also hopeless. For, according to Thomasson, our ordinary ways of talking are such as to make the inferential steps obviously justified. At which point, the only way to contest the inferential steps is to propose an alternative way of speaking; one which does not license such inferences.

This leads Thomasson to draw the following conclusion:

If we ask a general existence question such as 'are there numbers?', 'are there properties', 'are there propositions', using those terms in the only sense they have-using the rules by which they are introduced into the language, the answer is a straightforward, easy 'yes'. If we are spoiling for a debate, we must undertake it on other territory: regarding whether we should use these terms, along with their customary rules of use, at all. ${ }^{2}$

\footnotetext{
2 Thomasson (2015, p. 41, 2016, p. 14; her emphasis). See also Thomasson (2015, pp. 39-40, 73, 77-78,
} $112,153,169)$. Thomasson describes her position as Carnapian. I shall not explore the link to Carnap, but 
My main interest here is in Thomasson's explicit invocation of ordinary language. Thomasson both assumes that the existence questions are (typically) being asked in ordinary language, and also argues that the transition rules used in the easy-arguments are analytic, grammatical, conceptual, or trivial rules of ordinary language. ${ }^{3}$ So, by investigating Thomasson's deflationary position, I hope to draw some general conclusions concerning what ordinary language can tell us about ontology.

\section{Bad easy-arguments and the Context Principle}

In this section, I shall show that ordinary language is much more complicated than Thomasson's easy-arguments suggest. To do this, I shall consider some bad easyarguments. These will force us to reflect on the complexities of ordinary language.

\subsection{Bad easy-arguments}

Thomasson is well aware that the easy-argument template is not generally valid. To see this, consider a bad easy-argument:

(1k) rain stopped the cricket match

(2k) rain put the kibosh on the cricket match

(3k) there are kiboshes ${ }^{4}$

In my ordinary vernacular, $(2 \mathrm{k})$ is a literal and legitimate inference to draw from $(1 \mathrm{k})$. But the move to $(3 \mathrm{k})$ is wholly illegitimate. And ordinary English supplies us with a brickload of bad easy-arguments:

(1) I did it for him

(2) I did it for his sake

(3) there are sakes 5

(1) you are smart

(2) you have lots of smarts

(3) there are smarts 6

\section{Footnote 2 continued}

I would emphasise that Thomasson's invocation of ordinary language is no part of Carnap's position (cf. Thomasson 2015, p. 44).

3 In her 2007, Thomasson tended to speak in terms of 'common sense'. In her 2015, she tends to speak in terms of 'ordinary language', 'ordinary usage' or 'ordinary English'. I do not think much hangs on the difference, not least since Thomasson (2015, p. 135) is explicit that her earlier 'defense of ordinary objects' (i.e. her 2007) was a prototype for her full-fledged programme of easy ontology.

4 Consider also 'dampener' in place of 'kibosh'.

5 Quine (1960, Sect. 4, pp. 48, 50) seems to be the first philosopher to have offered this example; he also considers 'behalf' in place of 'sake'. Thomasson (2015, p. 265) explicitly considers this easy-argument for 'sakes', and I consider her response in Sect. 2.3.

6 Thomasson (2013, pp. 20-21, 2015, pp. 198-200) discusses 'smarts' when contrasting her position with fictionalism, though does not discuss what they tell us about easy-arguments. 
(1) she indicated her disdain for metaphysics

(2) she cocked a snook at metaphysics

(3) there are snooks 7

(1) he got jittery

(2) he got the heebie-jeebies

(3) there are heebie-jeebies 8

(1) I cheered up

(2) I found my happy

(3) there are happies 9

In every case, the transition from (1) to (2) is acceptable in my vernacular, but the transition to (3) is unlicensed. In what follows, I shall focus on the example of 'kiboshes', but everything I say straightforwardly applies to 'sakes', 'smarts', 'snooks', 'heebiejeebies', 'happies', and the like.

\subsection{Applying the Context Principle}

If there are bad easy-arguments, then we must ask what separates the good from the bad. I shall provide my own answer in this section, before considering two alternative answers in Sect. 2.3.

An obvious thought is that $(2 \mathrm{k})$ is nothing but a restatement of $(1 \mathrm{k}) .{ }^{10} \mathrm{Granted}$, at a purely syntactic level, one might say that $(2 \mathrm{k})$, unlike $(1 \mathrm{k})$, involves a three-place predicate ' $x$ put $y$ on $z$ '. But treating (2k) as being of that form, in any significant sense-that is, so that the inference to $(3 \mathrm{k})$ is to be regarded as "valid in virtue of its form' - would obviously be a mistake.

Having appreciated this, though, we must revisit all of the easy-arguments which Thomasson wants to endorse, and ask why we should not say the same thing about them. I shall start by examining the easy-argument for numbers, and return to the other easy-arguments in Sect. 2.4.

The easy-argument for numbers requires that we treat $(2 n)$ as being (significantly) of the following form:

$$
\overbrace{\text { the number of bagels }}^{\text {term }} \overbrace{\text { is }}^{\text {predicate }} \overbrace{\text { four }}^{\text {term }}
$$

\footnotetext{
7 The OED defines 'snook' as 'a derisive gesture'. If that definition is correct, it seems to license the inference to 'there are snooks'. However, the only examples of the use of the word 'snook' presented in the OED occur in the context of the phrase 'cocking a snook'; cf. what I say about the Context Principle in Sect. 2.2, and my comments on dictionaries in Sect. 3.4.

8 Consider also 'creeps' in place of 'heebie-jeebies', and see Musgrave (1989, p. 388) on 'creeps-realism'.

${ }^{9}$ Consider also 'mojo' in place of 'happy'. This case raises a further issue: 'I found my mail' does not allow us to infer 'there are mails' but 'there is mail'; so even the crudest syntactic test does not license the inference from 'I found my happy' to 'there are happies'. Ultimately, though, this is just more grist to my mill.

10 This is how Thomasson (2013, p. 21, 2015, pp. 199-200) describes the case of 'smarts' (see footnote 6, above). Cf. also Musgrave (1989, p. 388) on 'creeps' (see footnote 8 , above).
} 
This will allow us to take the quantificational step to (3n). But, for everything said so far, we could equally read ( $2 n)$ as follows:

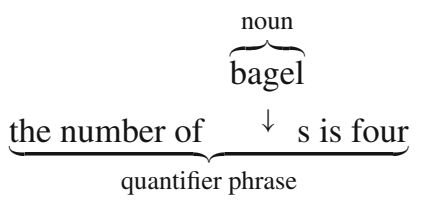

which is obviously just a variant of (1n):

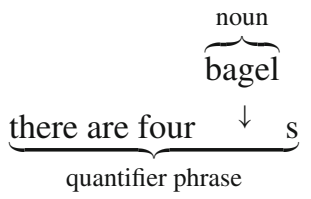

and which removes the temptation to infer (3n). So, if we want to embrace (1n)-(3n) as good whilst rejecting (1k)-(3k) as bad, then we face a compulsory question: Why does 'the number of bagels' behave as a genuine term in (2n), whereas 'the kibosh' does not so behave in $(2 k)$ ?

If we consider (2n) and (2k) as isolated sentences, there is really nothing to tell between them. So, if we are to answer our compulsory question without appealing to anything beyond ordinary usage, then we must examine the wider practice within which we say things like $(2 n)$. With that in mind, here are some further claims from that wider practice:

(in) the number of bagels, i.e. four, is the same as the number of people who ate brunch, and twice the number of packets of lox they consumed

(iin) there are infinitely many even numbers, and four is one of them

(iiin) there are exactly four prime numbers between 0 and 10

If anything makes it legitimate to treat numerical terms like 'four' as (purportedly) referring expressions in ordinary language, then it is the panoply of such claims. That is why we should admit that 'four' genuinely behave as a term in (2n). By contrast, there are no similar claims concerning 'kiboshes', and that is why we should deny that 'the kibosh' genuinely behaves as a term in (2k).

I shall say more about this this in the next subsection. But first, it is worth summarising the above point in terms of a general Context Principle. When asking for the meaning of a phrase, we should neither consider it in isolation, nor merely in the context of an individual sentence; rather, we must consider it in the context of an entire practice. ${ }^{11}$ Then, and only then, can we assess whether an easy-argument is good or bad.

\footnotetext{
11 Frege's Context Principle tells us 'never to ask for the meaning of a word in isolation, but only in the context of a proposition' (1884, p. xxii). Wittgenstein's Context Principle locates the meaning of a word within the context of a language game (1953, p. 49). So my formulation of the Context Principle is perhaps more Wittgenstein than Fregean. Nevertheless, Frege's and Wittgenstein's formulations can be linked, by maintaining that a sentence (considered as a string of words) only expresses a proposition when situated within a discourse. Davidson (1967, p. 308) seems to have drawn this link explicitly: 'Frege said that only
} 


\subsection{Ruling out alternative solutions}

Bad easy-arguments present a challenge for easy ontology. The Context Principle provides a solution to that challenge. However, I shall eventually argue that this solution has some unfavourable consequences for easy ontology. So, before going any further, I must consider and reject two alternative solutions to the challenge posed by bad easy-arguments.

One might think that bad easy-arguments merely threaten to show that easy ontology has some counter-intuitive consequences. But, if that were the full extent of the problem, then the easy ontologist could simply maintain that every easy-argument is good. She would thereby avoid the need to explain what makes an easy-argument good or bad, at the cost of counter-intuitively countenancing 'kiboshes'. ${ }^{12}$

It is vital, then, to understand that counter-intuitiveness is not the issue here. Bad easy-arguments present a challenge which is less about metaphysics than it is about language (at least, initially). The essential point is that, even if 'there are kiboshes' is grammatical-which is doubtful-it is totally unclear what it means. There are two options, and neither is favourable to easy ontology.

The first option is to regard 'there are kiboshes' as meaning exactly the same as 'something stops something'. In that case, we can merrily affirm (3k)—in some mild expansion of ordinary English — and maintain that it follows from (1k). However, so understood, we could not also maintain, with a straight face, that (3k) answers the initially intended existence question. Granted, (3k) is a sentence which begins 'there are ', but that tells us very little. The sentence 'there are kiboshes and carrots' would be at best a droll pun; a zeugma, on a par with 'I pressed my trousers and the point home'.

Consequently, if we want to use (3k) to answer an existence question, we must maintain that 'there are kiboshes and carrots' is on a par with 'there are cups and carrots'. This is the second option. But in this case we should be free to ask questions about the nature of kiboshes, just as we are free to ask questions about cups. So: What are kiboshes like? When are two kiboshes the same? When the same storm stops two adjacent cricket matches, do we have two overlapping kiboshes? When is one kibosh larger than another? And so on. These are all obviously nonsense questions, and with good reason. Our language only assigns a meaning to the two-place predicate ' $x$ put the kibosh on $y$ ', and not to the meaning of the word 'kibosh' as a noun in its own right. So: we can say 'there are kiboshes', if we really want to; but we cannot thereby affirm existence.

In providing my own solution to the problem of bad easy-arguments in Subsect. 2.2, I mentioned a Context Principle. This should make us think of Frege, and in fact the foregoing discussion is really just a variation on a Fregean theme. To make it explicit,

\section{Footnote 11 continued}

in the context of a sentence does a word have meaning; in the same vein he might have added that only in the context of the language does a sentence (and therefore a word) have meaning.' (Thanks to Rob Trueman for discussion on this, and for the reference from Davidson).

12 Thanks to Neil Barton and Richard Gaskin for (independently) suggesting that I consider this. Cf. Thomasson $(2015$, p. 265n8). In fact, it is implausible to think that all easy-arguments are good, since there are putative easy-arguments that generate flat-out inconsistency (see Thomasson 2015, pp. 253-72); however, such arguments are not my concern here. 
recall that Frege considers the idea of simply defining certain numerical expressions as follows:

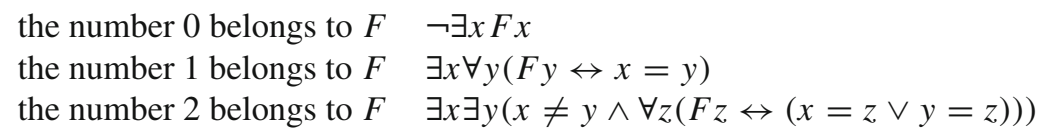

and so on. But Frege immediately criticises this, pointing out that in this case

we should be unable to justify the expression 'the number which belongs to the concept $F^{\prime}$.... It is only an illusion that we [would] have defined 0 and 1 ; in reality we have only fixed the sense of the phrases:

'the number 0 belongs to'

'the number 1 belongs to'

but we have no authority to pick out the 0 and 1 here as self-subsistent objects that can be recognised as the same again. ${ }^{13}$

For present purposes, the point is as follows. If you think that all easy-arguments provide good answers to existence questions, then you have fallen victim to the 'illusion' which Frege highlighted.

Everyone, then, must accept that there are bad easy-arguments. And Thomasson herself accepts this. Moreover, she has her own explanation as to what makes them bad. Thomasson maintains that bad easy-arguments involve a concept with applica-

13 Frege (1884, p. 56, Frege's emphasis). One might say, then, that Frege was the first philosopher to criticise easy-arguments. Indeed, there is a rich history of engagement with such arguments.

Trueman (2014, p. 370n22) suggests that this kind of argument is present in Wittgenstein's (1931-1934, p. 315) cryptic criticism of Ramsey's logicism.

Wilfred Sellars (1956, Sects. 8ff.) considers an easy-argument like the following:

(1) the rug appears red to me

(2) the rug presents me with a red sense datum

(3) there are sense data

Sellars agrees that it is fine to infer (2) from (1), provided that you read (2) as a mere variant on (1); however, that reading bars the inference to (3).

Quine (1960: see footnote 5, above) considers both the easy-argument to 'sakes', and also an easy-argument to the existence of units of measurement, such as:

(1) the race is 26.2 miles long

(2) there are 26.2 miles between the start and the finish of the race

(3) there are miles

Quine rejected such easy-arguments, on the grounds that we are in the presence of 'defective nouns: they are normally used only in a limited selection of the usual term positions. Their defectiveness...is easily exposed in absurd interrogation: Are miles alike? If so, how can they count as many? And if they cannot, what of the two hundred between Boston and New York?' (1960, p. 50).

David Lewis (1973, p. 84) presents us with this easy-argument:

(1) things might be otherwise than they are

(2) there is a way things could have been, besides the way they actually are

(3) there exist ways things could have been, i.e. possible worlds

Subject to certain caveats, Lewis suggested that this creates a 'presumption' in favour of taking 'seeming existential quantifications in ordinary language at their face value' (1973, p. 84). However, Lewis was careful to flag these caveats and, by the time he wrote his 1986, any hint of endorsing this easy-argument had drifted away; for the whole point of his 1986 is to defend (3) via a lengthy, difficult, cost-benefit analysis. (Thanks to Mark Sainsbury for drawing my attention to these features of Lewis.). 
tion conditions but with no coapplication conditions. Her point is that we know (for example) when to apply the concept kibosh, for we know when to utter sentences of the form ' $x$ put the kibosh on $y$ '; however, we have no idea when to say whether two kiboshes are one and the same. ${ }^{14}$

Thomasson's reaction to bad easy-arguments evidently has something in common with my invocation of the Context Principle. After all, both Thomasson and I have raised difficulties with the idea of saying that two 'kiboshes' are the same. However, my response is importantly different from Thomasson's. It is not just that we do not know when to say when two 'kiboshes' are the same: we also have no ability to ostend 'kiboshes'; to compare 'kiboshes'; or, indeed, to say anything about 'kiboshes'. (Compare and contrast the situation here with the case of numbers, discussed above, and with what I shall say about events and colours in Subsect. 2.4.) To repeat the Fregean point: we have only fixed the meaning of the two-place predicate ' $x$ put the kibosh on $y$ '. So it is not just that we do not know when to say 'this kibosh $=$ that kibosh'; we do not even yet know what such a phrase could mean. Consequently, it is a mistake to say that there is a monadic concept, kibosh, with application conditions but without coapplication conditions. There is not yet even a concept of the right shape.

If we do not yet have a monadic concept, kibosh, it is worth asking what it would take for ordinary language to provide us with such a concept. Given the above, an obvious suggestion is the following. Suppose that, in addition to all of the sentences of the form

$$
x \text { put the kibosh on } y
$$

we also had a range of sentences of the form

$$
\text { this kibosh }=\text { that kibosh }
$$

In that case, one might hope that these provide us (respectively) with application and coapplication conditions for a concept kibosh, so that in a language containing such sentences we would be able to infer from 'rain put the kibosh on the cricket match' to 'there are kiboshes' in a way which genuinely affirmed the existence of 'kiboshes'.

However, developing a point due to Robert Trueman, ${ }^{15}$ even this is doubtful. So far, it is only uncontroversial that there are circumstances in which it would be appropriate to produce sentences of two kinds of shape, both of which happen to contain the inkmark 'kibosh'. However, it is obvious that the ink-mark 'hat', as it occurs in 'this kibosh $=$ that kibosh', is not a term which refers to headwear. For similar reasons, it is debatable whether 'this kibosh' genuinely behaves as a term, and whether the ink-mark '=' genuinely expresses identity, in sentences of the shape 'this kibosh = that kibosh'. And, if not, we still cannot affirm the existence of 'kiboshes'.

\footnotetext{
14 Thomasson (2015, pp. 264-266). See also Quine (1960, p. 50).

15 Trueman (2014) offers an excellent criticism of neo-logicism, whose core is as follows. The only statements the neo-logicist can work with are those supplied by Hume's Principle. However, in Thomasson's terms, Hume's Principle aims only to provide us with application and coapplication conditions. Trueman then argues that these aims are insufficient to introduce us to the concept number. Consequently, Hume's Principle fails even to provide us with application or coapplication conditions; it merely pairs up two shapes of sentences.

This a good point for me to mention that the material in this subsection would certainly not have existed, had it not been for the many discussions I have had with Rob Trueman over the past few years.
} 
This prompts a deep question: At what point should we become convinced that an expression genuinely behaves as a term (in some sentence of some language)? I do not have a general answer to that question. There will be cases where it is wholly unreasonable to deny that we have a genuine term, cases where it is wholly unreasonable to maintain that we have a genuine term, and most likely a broad spectrum of cases in-between. Ordinary language is a wildly complicated phenomenon.

\subsection{Not-so-easy ontology}

In the previous subsection, I criticised some alternative solutions to the challenge posed by bad easy-arguments. Henceforth, I shall take it as established that the easy ontologist must adopt my Context-Principle-based solution, as outlined in Subsect. 2.2. I now want to explain that my solution comes with a catch: it indicates that 'easy' ontology is something of a misnomer.

The essence of the problem can be stated briefly. Suppose that existence questions can and should be answered just by reflecting upon ordinary usage. (To be clear: this supposition is controversial, and I shall ultimately reject it.) Even then, a good answer along these lines will require a careful examination of the rich variety of ways in which we ordinarily speak. So, there is no guarantee that existence questions are easily answerable.

That is the essence of the problem, but it needs refining. For a start: whilst there is no guarantee that existence questions can be answered straightforwardly, we might get lucky in certain cases. Indeed, I envisage the following defence of easy ontology: ${ }^{16}$

To assess the easy-argument (1n)-(3n), I concede that we must invoke the Context Principle. But this does not yet make ontology difficult. After all, anyone who is competent in using numerical terms will be equally competent in handling the claims (in)-(iiin) from Subsect. 2.2. And such claims show that 'the number of bagels' really does behave as a term in $(2 n)$. So, on the basis of claims that lie readily to hand for an ordinary speaker, we can easily see that the easy-argument (1n)-(3n) is good.

I am sympathetic to this line of thought, in the specific case of numbers. Crucially, though, this point does not generalise to all of the easy-arguments that Thomasson endorses. To show this, I shall consider them case-by-case.

The case of events seems broadly comparable to the case of numbers. If anything demonstrates an 'ordinary' commitment to events, it is not (1e), nor (2e), nor any array of claims of that shape. Rather, it is the wider fact that we are all perfectly prepared to make claims like these:

(ie) that [pointing] is an exemplary Fosbury Flop

(iie) the First World War and the Great War are one and the same

(iiie) the cricket match and the baseball match started simultaneously, but the former outlasted the latter by four days, and was rather more exciting

16 Thanks to Peter Hulme for raising this point. 
Respectively, these sentences seem to involve us ostending events, identifying them, and comparing them in multiple ways.

Initially similar thoughts apply to colours. If anything demonstrates an 'ordinary' commitment to colours, then Michael Dummett is surely right that it is our ordinary willingness to make claims like these: ${ }^{17}$

(ic) this colour [pointing] is the colour red

(iic) the colour of my rug is the same as the colour of my mug

(iiic) red is warmer than blue, it is complementary to green, and it lies between orange and purple

Again, we have apparent ostension, identification and a rich range of comparisons. However, (ic)-(iiic) are couched in terms of colours, whereas Thomasson's original easy-argument, (1p)-(3p), was couched in terms of properties. So if (ic)-(iiic) are to be used to defend any easy-argument, it will not be the easy-argument (1p)-(3p), but instead the alternative easy-argument:

(1c) that rug is red

(2c) the colour of that rug is red

(3c) there are colours

Indeed, the case of properties per se (as opposed to colours) turns out to be surprisingly difficult. Thomasson believes that we can always transition from predications to properties, and so endorses all easy-arguments with this shape: ${ }^{18}$

$\left(1 \mathrm{p}^{\prime}\right) a$ is $F$

$\left(2 \mathrm{p}^{\prime}\right) a$ has the property of being $F$

(3p) there are properties

But Dummett gave us excellent reasons to doubt this. Consider this example: ${ }^{19}$

$\left(1 \mathrm{p}^{\prime \prime}\right)$ slobber is slimy

$\left(2 \mathrm{p}^{\prime \prime}\right)$ slobber has the property of being slimy

$\left(3 \mathrm{p}^{\prime \prime}\right)$ there is a property (of sliminess)

Given the discussion in Subsect. 2.2, if we want to defend this easy-argument, then we must vindicate this reading of $\left(2 \mathrm{p}^{\prime \prime}\right)$ :

$$
\overbrace{\text { slobber }}^{\text {term }} \overbrace{\text { has }}^{\text {predicate }} \overbrace{\text { the property of being slimy }}^{\text {term }}
$$

rather than this alternate reading:

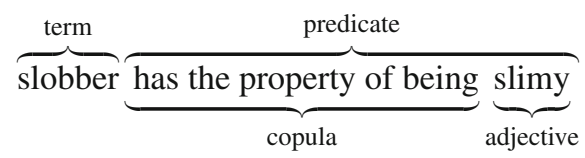

\footnotetext{
17 Dummett (1956, pp. 498-501, 1981, pp. 72-80).

18 Thomasson (2015, pp. 234, 258).

19 Dummett (1981, pp. 77-79).
} 
which can be regarded as a mere variant of $\left(1 \mathrm{p}^{\prime \prime}\right)$ :

$$
\overbrace{\text { slobber }}^{\text {term }} \overbrace{\underbrace{\text { is }}_{\text {copula }} \underbrace{\text { slimy }}_{\text {adjective }}}^{\text {predicate }}
$$

If we want to vindicate the first reading, without looking beyond ordinary language, then we must deploy the Context Principle. But, as Dummett notes, wider practice does not afford us a rich range of usage for the expression 'property of being slimy', or 'property of sliminess'. We do not ostend 'the property of sliminess', but slimy things such as slobber. ${ }^{20}$ We do not make a wide range of identity claims in which the identified object is 'the property of sliminess'. And we lack a rich range of comparatives concerning 'the property of sliminess'. Moreover, even if we were to find a vernacular which treated 'the property of sliminess' in a suitably rich sense, we should expect there to be further subtle variations concerning different predicates, across different vernaculars, and across different languages. None of this can be settled once and for all, via a priori means. And none of it can be settled without a huge amount of (linguistic) effort.

The case of propositions is much the same as the case of properties. ${ }^{21}$ In considering the argument (1t)-(3t), Thomasson requires that we read (2t) as:

$$
\overbrace{\text { the proposition that Tillman is a bulldog }}^{\text {term }} \overbrace{\text { is true }}^{\text {predicate }}
$$

rather than as follows:

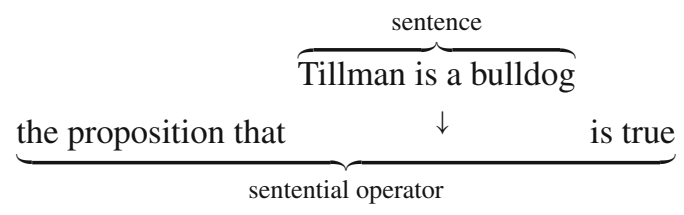

where the sentential operator is essentially redundant, but might add emphasis, as in

$$
\underbrace{\text { verily } \overbrace{\text { Tillman is a bulldog }}^{\substack{\text { sentence } \\ \downarrow}}}_{\text {sentential operator }}
$$

To vindicate the first reading, we would need to become convinced that ordinary usage involves us in (for example) indicating, identifying, and comparing propositions as

\footnotetext{
20 NB: I am not suggesting that every object must be capable of ostension. My point is simply that (apparent) ostensions can help to convince us that we are genuinely dealing with objects; and whereas we do ostend colours, we do not ostend the property of sliminess.

21 Which is no surprise, when we regard sentences as 0-place predicates.
} 
such. And perhaps a careful analysis of ordinary usage might eventually convince us one way or the other. However, we should expect that analysis to be genuinely difficult. $^{22}$

I began this subsection by noting that there is no guarantee that it will be an easy task to determine whether or not any given easy-argument is good or bad. I have bolstered this point: the task is sometimes very difficult indeed. In short: easy ontology ain't easy.

With that said, I should come clean, and note that this does not contradict Thomasson's official statement of easy ontology. In the careful formulations of her programme, Thomasson explains that she is not using the word easy in its ordinary sense. Rather, it is to be read in a 'technical sense', as a shorthand for the idea that 'no epistemically metaphysical work is required' in answering existence questions. ${ }^{23}$ So, Thomasson herself allows for the possibility that easy ontology can be time-consuming, complicated, and so forth.

I shall revisit this idea of distinctively 'epistemically metaphysical work' in Subsect. 4. Here, though, I shall simply offer three reasons-in increasing order of importance-for why I have spent several pages explaining why, and how, easy ontology ain't easy.

First: even if the official formulations of a programme are careful, slogans and brand names can be misleading. If they are not contested, then their rhetorical impact can be hard to dislodge.

Second: Thomasson repeatedly describes the inferences in her favoured easyarguments as 'trivial'. ${ }^{24}$ Unless 'trivial' is meant in a suitably technical sense, this is wrong. The putative inferences to the existence of properties or propositions are highly non-trivial, and even if they are ultimately legitimate inferences, this has yet to be shown.

Third: the need for easy ontologists to invoke a Context Principle indicates a deep connection between a self-consciously 'neo-Carnapian' approach to metaphysics, and approaches that are more inspired by Frege. ${ }^{25}$ And I will crucially exploit that connection in the next section.

To be clear, then: for everything I have said so far, it remains possible that existence questions can and should be answered just by considering ordinary language. All I have shown is that such answers are sometimes difficult to obtain, since they must always take into account the Context Principle.

\footnotetext{
22 And if you doubt this, consider the classic exchange between Austin (1950) and Strawson (1950).

23 Thomasson (2015, p. 329), see also Thomasson (2015, pp. 17, 45n12, 113-4, 128-9, 158, 173, 204-5, 249, 270, 295, 319-21, 326-30).

24 Thomasson (2007, pp. 159, 162-3, 2009b, p. 6n8, 2013, pp. 1023, 1025-1030, 1033, 1036, 1038-1040, $1045,1049,2015$, pp. 14, 21, 33-34, 39, 47-50, 56, 73, 111, 127-132, 134-135, 136-156, 159, 172173, 180, 191-196, 202-203, 205, 217, 219, 221, 229-232, 247, 251-254, 257, 273-276, 280, 282-284, 290-293, 296, 301, 318, 323, 2016, pp. 2, 7-8, 14, 16-17, forthcoming, pp. 1-16).

25 Thomasson (2015, pp. 132-145, forthcoming, Sect. 1) suggests that her easy ontology generalises several other deflationary projects, including: Schiffer's pleonastic platonism; Hale and Wright's neo-Fregeanism; and Blackburn's and Price's quasi-realism. She does not, though, discuss any version of a Context Principle.
} 


\section{Mereology and ordinary usage}

I now want to show, though, that there is no reason to hope that certain existence questions can be settled just by considering ordinary language. In particular, I shall take the debate surrounding mereology as a case study. This is significant, since almost every metaphysical deflationist takes the mereology debate as their favourite example of a supposedly pointless debate. To put the point crudely: since easy ontology cannot even beat up the punchbag of contemporary metametaphysics, there is something amiss with easy ontology.

\subsection{An argument for universalism}

Thomasson believes in ordinary composite objects, such as tables. Indeed, she is happy to defend their existence via an easy-argument: ${ }^{26}$

(1m) these are particles arranged tablewise

(2m) this thing is a table

(3m) there are tables

(For what it is worth, I am sympathetic to the soundness of this argument. However, given the discussion of Sect. 2, we should not expect that it will be easy to establish its soundness. I will reinforce this point from Sect. 3.3 onwards.)

Thomasson, however, goes well beyond countenancing tables. Indeed, she maintains that easy ontologists should embrace mereological universalism (henceforth simply universalism). I shall reconstruct her argument to this conclusion in five steps. ${ }^{27}$

Step 1. Consider the question: Which composite entities exist? One answer is: Exactly those entities, for which we have simple words in ordinary English. Crudely, the idea is that we can answer the question just by picking up a contemporary English dictionary and highlighting all the nouns which are supposed to apply to composites. But this answer-indeed this whole approach-seems much too parochial. ${ }^{28} \mathrm{We}$ all know that we could have spoken differently; indeed, that our dictionaries have changed

\footnotetext{
26 Thomasson raises two minor points about this argument which are well worth noting. First: since the expression 'particles arranged tablewise' is a philosopher's invention, (1m)- $(3 \mathrm{~m})$ may well not qualify as an argument of ordinary English. Nonetheless, the argument is dialectically appropriate in the context of the mereology debate, and it may be offered in a suitable extension of ordinary English where all parties are happy to use this new expression (see Thomasson 2015, pp. 106-107, 150). Moreover, had we preferred, we could instead have considered (as an anonymous referee suggested) an argument in plain English such as:

$\left(1 \mathrm{~m}^{\prime}\right)$ he built a table

$\left(2 \mathrm{~m}^{\prime}\right)$ there is a table which he built

$\left(3 \mathrm{~m}^{\prime}\right)$ there are tables

Second: Thomasson does not need to provide an inference to $(2 \mathrm{~m})$. Instead she could simply start with a paradigm instance of $(2 \mathrm{~m})$, as uttered in ordinary English perhaps while ostending a table (see Thomasson 2015, pp. 141-144). Nothing I say in criticism of Thomasson will exploit either point.

27 Particularly drawing on Thomasson (2007, pp. 183-185).

28 Thomasson (2015, pp. 214-215) claims that easy ontology pleasingly avoids parochialism.
} 
and will continue to change. The nouns we happen to have are just the ones we happen to have.

Step 2. So consider any particles you like, arranged anyhow. We could, in principle, add a word to our language - perhaps 'gluggle' — to deal with exactly those particles, arranged thathow. By such means, 'gluggle' would come to have perfectly reasonable rules for use: encountering particles arranged 'glugglewise', we are to say 'this thing is a gluggle'. And, given the considerations of Step 1, it would be hopelessly parochial to object that this is an illegitimate addition to our language.

Step 3. In future-speak, we will then have an easy-argument:

(1g) these are particles arranged glugglewise

$(2 \mathrm{~g})$ this thing is a gluggle

$(3 \mathrm{~g})$ there are gluggles

And, given that the argument $(1 \mathrm{~m})-(3 \mathrm{~m})$ is good, so is the argument (1g)-(3g). To think otherwise would, again, be horribly parochial. So we must accept that $(3 g)$ is true in future-speak. ${ }^{29}$

Step 4. Observe that future-speak differs from present usage only by the addition of the word 'gluggle' (and maybe 'glugglewise'). This tiny alteration should not suffice to change the meaning of the word 'exists'. For if it did, then there would not be enough stability in the word 'exists', over time and across vernaculars, to account for communication. So we should accept that the word 'exists' has the same meaning in future-speak as it does now. And, according to Thomasson, the 'core rule' for 'exists' is given as follows:

\section{$K$ s exist iff the application conditions actually associated with ' $K$ ' are fulfilled. ${ }^{30}$}

If the rule has not changed, then ' $K$ s exist' is true (in future-speak) iff the (actual) application conditions for the (future) word ' $K$ ' are met. Since ( $3 g$ ) is to be true, we can conclude that the entities which we shall call 'gluggles' exist (already). ${ }^{31}$

Step 5. But the word 'gluggle' was a schematic placeholder: we noted that any particles, arranged anyhow, could be picked out by that word. So we conclude that any particles, arranged anyhow, constitute an entity. ${ }^{32}$ And that is universalism.

\footnotetext{
29 In conversation, Teru Thomas raised the following interesting objection to this Step. Given the morals of Sect. 2, we may not have introduced a sufficient range of uses of the word 'gluggle' for us to succeed in successfully introduced a bona fide concept. Consequently, (1g)-(3g) might be a bad easy-argument, even whilst $(1 \mathrm{~m})-(3 \mathrm{~m})$ is good. There is much more to say here. However, I shall not pursue this point, except to note that it once again illustrates just difficult easy ontology can be.

30 Thomasson (2015, p. 86). See also Thomasson (2008, pp. 64-67, 2009b, pp. 3-5, 2009a, pp. 453-454, 2015, pp. 83-89, 2016).

31 See Thomasson (2009b, p. 14, 2015, pp. 217-220).

32 Though I shall not pursue it in what follows, I am extremely suspicious of this inference. It is reasonable to hold both that adding a single grain of sand to a non-heap never yields a heap, and that adding sufficiently many grains of sand to a non-heap yields a heap. Similarly, then, it seems reasonable to hold both that adding the word 'gluggle' to our vocabulary, together with the claim 'there are gluggles', does not shift the meaning of 'exists', but that embracing universalism would involve a shift in the meaning of 'exists'. My point is simple: if meanings are objects, then they are as vague as heaps.
} 


\subsection{Universalism and ordinary English}

Something rather strange has happened: considerations concerning ordinary usage have supposedly led us to embrace universalism. This extraordinary conclusion demands investigation.

Thomasson is of course aware of the potential tension between advocating universalism and focussing on ordinary usage. In an attempt to smooth it away, she writes:

it is true that common sense does not recognize the existence of [gluggles], mereological sums, and the like. Nor, of course, does it deny their existencethere are no terms in ordinary English for these things, and common sense understandably does not consider such things at all.... ${ }^{33}$

Thomasson maintains, then, that ordinary English speakers do not and could not deny universalism, since they (currently) lack the vocabulary even to formulate universalism.

Even if we grant Thomasson this point, the tension between her advocacy of universalism and ordinary usage goes deeper than her reply suggests. As Peter van Inwagen notes ${ }^{34}$ universalism entails plenty of extraordinary claims which involve no mereological vocabulary at all. To give us a working example, let the Two Table Room contain what the untutored will describe as two wooden tables, both of which are exactly $30 \mathrm{~kg}$, and nothing else. If universalism is right, then any arbitrary fusion of table parts is itself an object. So, some scattering of parts from the two tables will make it correct to say:

(M) something in the Two Table Room is exactly $51 \mathrm{~kg}$

This is a sentence of ordinary English. But it seems like an extraordinary thing to say. I expect that most ordinary English speakers would reject (M), or be confused as to why it has been said, or search in vain for some $51 \mathrm{~kg}$ object. But Thomasson must maintain that (M) is nevertheless true.

Evidently, Thomasson needs a theory to account for the slippage between what the folk judge, and what she insists is true. Fortunately, she has a theory to hand. According to Thomasson, we should distinguish at least two uses of existential quantification. ${ }^{35}$ Sometimes, we use the quantifier to pick out roughly contiguous objects, for example. Read thus, (M) is clearly false: the table parts which would supposedly make it true are diversely scattered. But there is also a 'covering usage' of existential quantification, which licenses any transition from a successful application of a sortal term (e.g. 'there is a table in the Room') to a sortally unqualified existential claim (e.g. 'there is a thing in the Room'). Read thus, Thomasson maintains that (M) is true. So, according to Thomasson, (M) is true when read with a 'covering usage' of the quantifier, but most speakers will reject (M) because they will tend to hear it with some other usage in mind.

\footnotetext{
33 Thomasson (2007, p. 183).

34 van Inwagen (2009, pp. 49-50).

35 Thomasson (2009a, pp. 458-462).
} 
Unfortunately, if this proposal is to remove all conflict between ordinary usage and universalism, then, for each mereological sum, there must be some ordinary sortal which applies to the sum in question. For if the sortal is itself extraordinary-as 'gluggle' is - then ordinary English does not license the transition to a bare (sortally unqualified) existential claim. And ordinary usage just does not have sufficiently many sortals. (Of course, if 'mereological sum', or some synonym were a sortal of ordinary English, then every sum would fall under some sortal. However, Thomasson has already told us that 'mereological sum' is not a term of ordinary English; see the quote at the start of this section.)

Thomasson has not, then, succeeded in removing the tension between ordinary usage and universalism. But I should be clear: this does not show that universalism is in conflict with the project of easy ontology itself. Perhaps there is some alternative background theory which, all things considered, both offers the best underpinning for ordinary English usage and also categorises (M) as true but extraordinary. That, in any case, is what Thomasson must hope for.

\subsection{Nihilism and ordinary usage}

I shall not try to argue that there is no such theory. Instead, in this section, I shall try to show the following: for any argument that ordinary usage pulls us towards universalism, there is an exactly analogous argument that ordinary usage pulls us in the opposite direction.

To show this, allow me to introduce a fictional philosopher, Nihal. Via reasoning like Thomasson's, Nihal has become convinced that ordinary usage pulls us towards nihilism. Here is why.

Nihal agrees with Thomasson on most of the Steps in the argument of Subsect. 3.1. Nihal warmly embraces Step 1: we cannot determine which composites exist, just by considering the nouns we happen to have in English right now. For the same reason, Nihal does not object at Step 2: no one can stop us from introducing a word, such as 'gluggle', to a language.

At Step 3, though, Nihal is more cautious. On pain of parochiality, Nihal agrees that the arguments $(1 \mathrm{~m})-(3 \mathrm{~m})$ and $(1 \mathrm{~g})-(3 \mathrm{~g})$ stand or fall together. For now, though, his commitment remains conditional.

At Step 4, Nihal agrees that adding the word 'gluggle' should not affect the meaning of 'exists'. So he commits to conditional: if the argument $(1 \mathrm{~m})-(3 \mathrm{~m})$ is sound, then the entities which we shall describe as 'gluggles' exist (already). And, wisely or not, Nihal also concedes the force of Step 5. So he commits to the following: if the argument $(1 \mathrm{~m})-(3 \mathrm{~m})$ is sound, then universalism is true.

But Nihal rejects universalism. He is not concerned that it is too ontologically profligate. He is not worried about issues concerning co-location. He has no fear of large-scale causal redundancy. ${ }^{36}$ (So, Nihal's reasoning is certainly not 'epistemically metaphysical'; see Subsect. 2.4, Sect. 4.) Rather, Nihal simply maintains that (M), and many similar claims entailed by universalism, conflict with ordinary English utter-

$\overline{36}$ Thomasson (2007) does an excellent job in rebutting these kinds of concerns. 
ances. So Nihal tollenses Thomasson's ponens. He rejects the argument $(1 \mathrm{~m})-(3 \mathrm{~m})$. And since Nihal is opposed to parochialism, Nihal comes to deny that any composites exist.

In sum: just as Thomasson affirms universalism, citing ordinary usage, so Nihal affirms nihilism, citing ordinary usage.

Nihal is, of course, aware that nihilism is in tension with ordinary usage. To smooth away the tension, he adopts van Inwagen's 'language of refuge'. ${ }^{37}$ He points out that there is no harm in saying $(2 \mathrm{~m})$, i.e. 'this thing is a table', so long as we understand this as saying no more nor less than $(1 \mathrm{~m})$, i.e. 'these are particles arranged tablewise'. (Compare this with the observation, from Subect. 2.2, that there is no harm in saying 'rain put the kibosh on the cricket match', if we understand this as saying 'rain stopped the cricket match'.) Indeed, Nihal continues, it may even be alright to affirm ( $3 \mathrm{~m})$, i.e. 'there are tables', so long as it is understood similarly. (Compare this with the observation, from Subsect. 2.3, that there is no harm in saying 'there are kiboshes', so long as we understand this as saying 'something stopped something'.)

Nihal's only sticking point is this. When speaking strictly, Nihal will describe the Two Table Room as follows: 'there are some particles arranged tablewise with a collective mass of $30 \mathrm{~kg}$, and some totally different particles arranged tablewise with a collective mass of 30kg'. But when it comes to the existence question of whether there are tables, and tables are singular composite entities, then, Nihal says: 'there are no tables'.

Nihal is mirroring Thomasson's strategy from Subsect. 3.2. He sincerely wants to respect ordinary English. He recognises conflict between nihilism and ordinary English. And so, in an attempt to save the phenomena concerning what we ordinarily say to each other-e.g. 'there are two tables in the Room'- - he offers a broad theory which allows for this to be true, when heard in terms of particles arranged tablewise, but strictly false when heard in terms of singular composites. (Compare this with Thomasson's suggestion that (M) is false, when the quantifiers are read in terms of roughly contiguous objects, but true when read with a covering usage.)

Can no wedge be driven between Thomasson and Nihal? One might attempt to do so, by insisting that it is clear that there are tables in the Two Table Room, but unclear whether there is a $51 \mathrm{~kg}$ thing in the Two Table Room. ${ }^{38}$ In that case, Nihal would be clearly wrong, but it would be unclear that Thomasson is. But this line of thought is question-begging, for two reasons. First, Nihal admits that he can hear a sense in which 'there are tables in the Two Table Room' is (clearly) true; his point is just that the sense in which it is true does not make contact with the relevant existence-question. (Recall again, from Subsect. 2.3, that there is no harm in saying 'there are kiboshes', so long as we understand this as saying 'something stopped something'.) Second, all of this ultimately depends upon empirical claims concerning what is clear (or not) to ordinary English speakers. Until we have a survey of their attitudes to hand, neither Thomasson nor Nihal can claim superiority here. But, even in the absence of a survey,

\footnotetext{
37 van Inwagen (1990, pp. 105, 109).

38 Anticipating the discussion of 'customary rules for use', below: this idea could be bolstered if we could establish that the 'customary rules for use' governing 'table' are somehow clearer than those governing 'thing'. Thanks to an anonymous referee for suggesting I consider these responses.
} 
I am willing to stick my neck out and make a prediction: ${ }^{39}$ most of those ordinary people who find it clear that there are tables in the Two Table Room will find it equally clear that there is no $51 \mathrm{~kg}$ thing there. Thomasson and Nihal are roughly as "clearly wrong' as each other.

For her part, Thomasson explicitly criticises a character like Nihal as follows:

the table-denier is not making any theoretic claim we can make sense of-since if he accepted the term 'table' with its customary rules of use, it would be an obvious truth that there are tables. ${ }^{40}$

But this complaint also fails to break the parity between Nihal and Thomasson. Nihal can offer an exactly analogous complaint:

Thomasson is not making any theoretic claim we can make sense of-since if she accepted ordinary words with their customary rules for use, it would be an obvious truth that nothing in the Two Table Room is $51 \mathrm{~kg}$.

In fact, both Thomasson and Nihal are in danger of misleading us here. Nihal is a fluent English speaker, and he understands that for a table to exist (strictly speaking) is for there to be a composite object located exactly where some particles arranged tablewise are. Nihal just denies that there are any composite objects. Thomasson is a fluent English speaker, and she is familiar with standard means for measuring the mass of medium-sized entities. She just thinks that weighing two tables simultaneously is a method for weighing a single object, ${ }^{41}$ from which the weights of smaller (partially overlapping) objects can be inferred. In short: both Thomasson and Nihal are familiar with the relevant 'customary rules of use'. The problem is that these 'customary rules' fail to decide between Thomasson's or Nihal's position.

Thomasson hints at a further consideration which might tell in her favour against Nihal. She suggests that 'normal' people could easily be brought to assert the doctrine of universalism, and so could equally be brought to assert (M):

suppose... that we explained to 'normal' people how the terms '[gluggle]' and 'sum of $x$ and $y$ ' were to be used.... Then simply ask them, for example, is there a [gluggle]...? I think in this case 'common sense', with a vocabulary suitably expanded to include the new term, would certainly accept that there is. (And much the same, I think, would go for the case of sums, once the whole language game of mereology was sufficiently introduced.) $)^{42}$

Now, I do not doubt that (most) people could be brought to speak in a way which led them to affirm (M). But if this is break the parity between Thomasson and Nihal, then we need some reason to think that (most) people could not equally be brought to speak

\footnotetext{
39 Note, though, that for reasons I shall develop in Subsect. 3.4, I would not mind if I were wrong about this.

40 Thomasson (2016, p. 13); Thomasson's italics. See also the references in footnote 2, above.

41 cf. Thomasson's $(2007$, p. 154) remark that the way to own a pair of gloves is just to own a left-glove and a right-glove which match.

42 Thomasson (2007, p. 184).
} 
Nihal's way; to adopt the language of refuge. And no such reason is forthcoming. Both ways of speaking are equally available.

We could keep going, but my point should be clear by now. Nihal can and will shadow Thomasson's every move. As such, Thomasson and Nihal's positions seem on a par: both advocate positions that involve some conflict with ordinary language, and nothing obviously tells between them. Now, I do not claim to have an shown that it is in principle impossible for Thomasson to triumph over Nihal, or vice versa, on the basis of considerations drawn solely from ordinary language. My point is just that there is no obvious reason to believe (or even to hope) that one of these two incompatible positions will win out over the other.

To be sure, there is a difference between Thomasson and Nihal. But it seems to come down only to this. Thomasson prefers to countenance hitherto-unrecognised entities (e.g. of arbitrary fusions), where Nihal prefers to retract positive affirmations of existence (e.g. of tables). And one might reasonably worry that this is mere prejudice, on both their parts.

Indeed, this worry can be bolstered by reaching back to the Context Principle, as raised in Subsect. 2.2. In defence of her position, Thomasson cites her favoured theory of reference which, she claims, 'underpins' ordinary usage. According to this theory, $K$ s exist iff the application conditions for ' $K$ ' are fulfilled. And, she maintains, the application conditions for 'table' and 'gluggles' are equally fulfilled, so that there is nothing more to say. But the preceding discussion indicates that there is more to say. As shown in Subsect. 2, to determine whether an easy-argument is good or bad-to determine, that is, whether we may infer that something exists-we must invoke the Context Principle. Otherwise put, if we are to determine whether there is a genuine term in the offing, then we must consider rich, widespread patterns of usage. But this means that there is no reason to follow Thomasson in venerating mere 'applications' of a concept - i.e. utterances of the form 'that is a $K$ ' - when we come to decide what to count as a true answer to an existence question. Indeed, there is no reason to venerate utterances of any particular form. Rather, we must consider all the ways in which a particular (putative) term can be used, as discussed in Subsect. 2.2. But, having done so, there is no neutral reason to insist that our initial endorsement of ( $2 \mathrm{~m})$ should 'trump' our initial rejection of (M), as Thomasson does, or vice versa, as Nihal does. In sum: the Context Principle ultimately puts the kibosh on any attempt to argue for either universalism or nihilism via easy ontology.

\subsection{Parochialism and ordinary usage}

I now want to move beyond universalism and nihilism, and consider a third alternative, which claims - mistakenly - to be more respectful to ordinary language.

In Subsect. 3.3, we considered Thomasson's suggestion that we might coach people in the language of 'gluggles' and 'sums'. She offered this as a way to make sense of the semantics of ordinary English; to make us see that (M) was really true all along, when heard the right way. I also noted that Nihal could suggest a similar coaching in the 'language of refuge'. But one might well take issue with the idea that this 'coaching' tells us anything about ordinary English. Instead, one might think that the 
process of 'coaching' amounts to teaching ordinary English speakers how to speak a new language, which is related to but distinct from ordinary English.

This is the line of thought advanced by Eli Hirsch. Like Thomasson, Hirsch describes himself as a neo-Carnapian who thinks that existence questions are to be settled by considerations of ordinary usage (if at all). But Hirsch holds that both Thomasson and Nihal are attempting to abandon ordinary English in favour of new ways of speaking. According to Hirsch, ordinary English embraces the existence of 'ordinary' objects, and so rejects nihilism, but it equally rejects (M), and so rejects universalism. 43

Hirsch, then, presents us with an alternative to both universalism and nihilism: stick, resolutely, to the ontology of ordinary English. In terms of the above, Hirsch effectively gets off the bus at Step 1 of the argument in Subsect. 3.1. That is, Hirsch is prepared to shrug off the accusation of parochiality. Consequently, I shall call his position parochialism.

In calling it parochialism, I am not cocking a snook at Hirsch. Ordinary usage enables us to cope with ordinary situations: predicaments which we actually encounter, to which we must respond. Ordinary usage is well-suited to this purpose, and this is no coincidence: had it been ill-suited, a better-suited usage would likely have sprung up in its place. Given its suitability for purpose, though, it is unclear why we should care that it is parochial. To be sure, if we wanted to determine what really and fundamentally exists, say, then the charge of parochiality would cut deep. But, if our aim was simply to cope with ordinary situations, then an accusation of parochiality will be no big bananas.

For the purposes of this paper, the important question is whether easy ontologists should embrace parochialism. The considerations of the previous paragraph might seem to support the idea that they should. After all, opposition to parochialism is a completely standard move in 'traditional' metaphysics. So, when Thomasson pitched easy ontology against parochialism in Step 1 of Subsect. 3.1, perhaps she embraced too much of 'traditional' metaphysics.

Certainly, parochialism a reasonable deflationary option. But parochialism is no more the unique way to pursue ordinary usage than is universalism or nihilism. To see why, I shall consider the parochialist's attempt to answer the question: What exists?

The parochialist will begin by saying that we must answer this question by appealing to ordinary usage. But that is not yet an answer. At best, it is the slogan of a methodology. To answer the question, the parochialist must determine what ordinary speakers actually say.

Now, in Subsect. 3.1, I crudely caricatured the parochialist as attempting to answer the question by flicking through a contemporary English dictionary. Even the parochialist will regard this as overly crude. Dictionaries get out of date; they straddle an interesting divide between descriptive and prescriptive uses of language; and, fundamentally, one can always ask whether or not the dictionary was compiled

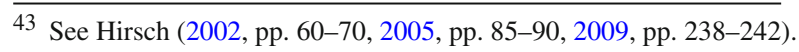


correctly. ${ }^{44}$ And all of these points bring us right back to the original question for the parochialist: what do ordinary speakers actually say?

The parochialist would do better, then, to conduct a thorough survey of ordinary English speakers. So, suppose the parochialist presents ordinary speakers with multiple questions of the form 'are there___ s?'. For simplicity, we shall suppose that this survey is conducted absolutely impeccably. By aggregating the answers, we might attempt to generate 'the ordinary theory of what exists'. Call this the Questionnaire Theory.

The results of the survey might well supply us with some interesting linguistic data. But when it comes to the matter of existence questions, the Questionnaire Theory is entirely useless. To illustrate its problems, consider these three incompatible claims:

(a) there are $K \mathrm{~s}$

(b) if there are $K \mathrm{~s}$, then there are $L \mathrm{~s}$

(c) there are no $L s$

It is entirely possible for a majority of people to affirm (a), a majority of people to affirm (b), and a majority of people to affirm (c), without anyone making an elementary logical mistake. And this situation is more than a merely abstract possibility; it is concretely realised by the three positions which I have considered in this section. Read ' $K \mathrm{~s}$ ' as 'tables' and ' $L s$ ' as 'entities which we shall refer to as "gluggles"'. Thomasson affirms (a) and (b), and so rejects (c). Nihal affirms (b) and (c), and so rejects (a). Hirsch affirms (a) and (c), and so presumably rejects (b). So, if the views of Thomasson, Nihal and Hirsch are equally represented in the population, then the Questionnaire Theory will have no internal coherence. It will be nothing but a list of words, for which a majority of people are prepared to say 'there are __s'. To call that a theory of what exists is to give it an honorific it just does not deserve.

\subsection{Philosophy and tension}

In this particular case, the parochialist might maintain that Thomasson and Nihal are victims of philosophical errors, which have caused them to abandon ordinary usage. But that would be a glib response to a deep problem. The deep problem is that ordinary usage is subject to a certain amount of tension; tension which the Questionnaire Theory cannot even acknowledge.

A basic philosophical experience is to be pulled in different directions by your 'ordinary' commitments. Some of these tensions can be brought out with nothing more than a pair of well-posed questions, whilst others take years of thought to expose. We encounter these tensions when we first read a Socratic dialogue; again when we are taught philosophy; still further when we teach it; and at every stage of honest reflection. So, for any given area of philosophical controversy, we should expect that our 'ordinary' usage will be subject to tensions which push us in different directions, and which undermine the idea that we could read a theory off from ordinary usage. Different people break in different directions in response to that tension. That, indeed, is how the (a)-(b)-(c) problem can even get started.

${ }^{44}$ Cf. Quine (1951, p. 24). 
Focussing on the particular case of mereology: the parochialist cannot legitimately maintain that she has remained philosophically innocent, or deliberately un-philosophical, whilst Thomasson and Nihal have been led astray by philosophical theorising. Looked at from the outside, we should say that all three parties have made different philosophical decisions in response to the latent tensions present in ordinary usage. Within ordinary usage, there is an undeniable pressure against parochialism towards either universalism or nihilism, as discussed during Step 1 of Subsect. 3.1. Equally, though, there is pressure against both universalism and nihilism, and hence back to parochialism. Of course, we can attempt to shrug off some of these pressures. But to do that is, as metaphysicians have always said, to 'bite a bullet'. How big a bullet was bitten? Well, that will vary from case to case. But just such questions are the bread and butter of 'traditional' metaphysics.

To round off this section, I shall link these thoughts back to the Context Principle of Sect. 2 once again. I have argued that, insofar as we can speak of 'the ontological commitments of ordinary usage', they must be determined by considering large-scale patterns of usage. But, as just noted, the entire experience of doing philosophy confirms that large-scale patterns of usage are typically shot through with tensions. So, if you are insistent on determining 'the ontological commitments of ordinary usage', you cannot simply conduct a parochial survey of ordinary usage; not even one which does more than merely asking a bunch of questions of the form 'are there ___s?' You must immerse yourself in a practice, and learn to feel its tensions, as its practitioners do. And then you must decide how to react to those tensions: to live with them, or to resolve them in one way, or to dissolve them in another. The decision can be taken explicitly or implicitly; through action or inaction. But these are different decisions, and there is no a priori reason to expect that one of them must be uniquely the right decision.

\section{The role of ordinary language}

We cannot, then, expect analysis of ordinary language to provide us with a catch-all method for avoiding the standard questions of metaphysics. Nevertheless, a central pillar of Thomasson's easy ontology remains untouched by the discussion so far. For nothing I have yet said contradicts her claim that we will never need to undertake distinctively 'epistemically metaphysical work' (see Subsect. 2.4). I shall close this paper by assessing this idea.

Contemporary metaphysics sometimes employs notions which I must confess I struggle to understand: in virtue of; fundamental; grounding; truth-making; jointcarving; natural; and so forth. Moreover, sometimes-though not always-these rather intractable notions are wielded in a way which makes metaphysics deliberately discontinuous from other concerns and areas of inquiry. Now, insofar as Thomasson is exhorting us to avoid philosophising in this way, I agree with her wholeheartedly. ${ }^{45}$ However, there is a large gap between rejecting that way of philosophising, and signing up to Thomasson's project.

$\overline{45}$ See e.g. Thomasson (2009a, pp. 295-317) and Button (2013, pp. 1, 177). 
In a deeply insightful passage, Thomasson suggests that deflationary approaches should 'renounce the search for reductive generalizations of the following form':

$K$ s exist iff

and she considers and rejects various past proposals for cashing out this biconditional, e.g., iff: $K \mathrm{~s}$ are causally potent; $K \mathrm{~s}$ are mind-independent; $K \mathrm{~s}$ are posits of our best scientific theory; $K$ s posses a real nature; etc. ${ }^{46}$ The desirability of such a reductive generalization is clear: crudely put, it would turn ontology into a craft comparable with plumbing. ${ }^{47}$ Rather than endlessly pontificating about whether and how one might even in principle solve certain problems, the reductive generalisation would equip us with some general tools and methods for actually solving those problems. Moreover, these methods would be tractable, but—like plumbing-probably best left to professionals.

I agree with Thomasson that this conception of ontology is - for better or worsefantastical. But, ultimately, Thomasson herself falls victim to a variant of it, when she provides her own generalization:

$K$ s exist iff the application conditions actually associated with ' $K$ ' are fulfilled. ${ }^{48}$

Thomasson regards her biconditional as importantly 'insubstantial', on the grounds that it is metalinguistic (contrast this with the reductive generalisations considered and rejected in the previous paragraph). But my concern with such reductive biconditionals is not with their 'substantiality', but with their ambition of turning ontology into a craft comparable with plumbing. Armed with the easy ontologist's biconditional, existence questions remain finicky enough to keep us in a trade, for reasons outlined in Sects. 23 , but tractable enough to be settled by restricting your attention to the analysis of ordinary language. This is just the image I find untenable.

In Subsect. 3.5, I commented that 'traditional' metaphysical questions can easily be motivated by attempts to resolve the implicit tensions in ordinary language. In fact, there are plenty of other sources of tension. Tensions arise from all sorts of our commitments, be they ordinary or scientific, mathematical or political, aesthetic or poetic, religious or ethical, or-often - some combination of all of these. Indeed, I am not really going out on a limb when I say: If there were no such tensions, then philosophy would not exist.

As in Subsect. 3.5, then, but with more potential sources of tension in play: it is a philosophical decision to live with those tensions; it is a different philosophical decision to attempt to relieve them; and we should not expect that there is a uniquely best way to relieve them. But crucially, since these tensions may be drawn from any areas of consequence (and not just from ordinary language), we should expect to have to answer questions which arise from any areas of consequence, or from their mutual interaction (and not just questions which arise from analysis of ordinary language).

\footnotetext{
46 See Thomasson (2015, pp. 88, 116).

47 To adopt an image which I think I took from Hugh Mellor (but neither of us is sure).

48 See footnote 30 .
} 
At its best, metaphysics just is the attempt to answer such questions, in an attempt to relieve such tensions, whatever their sources. ${ }^{49}$

Open Access This article is distributed under the terms of the Creative Commons Attribution 4.0 International License (http://creativecommons.org/licenses/by/4.0/), which permits unrestricted use, distribution, and reproduction in any medium, provided you give appropriate credit to the original author(s) and the source, provide a link to the Creative Commons license, and indicate if changes were made.

\section{References}

Austin, J. L. (1950). Truth. In Proceedings of the Aristotelian Society, supplementary volume 24, (pp. 111-172).

Button, T. (2013). The limits of realism. Oxford: Oxford University Press.

Davidson, D. (1967). Truth and meaning. Synthese, 17(3), 304-323.

Dummett, M. (1956). Nominalism. The Philosophical Review, 65(4), 491-505.

Dummett, M. (1981). Frege: Philosophy of language (2nd ed.). London: Duckworth.

Frege, G. (1884). Die Grundlagen der Arithmetik: Eine logisch mathematische Untersuchung über den Begriff der Zahl (J. L. Austin. (1953), Black-well Trans.). Wilhelm Koebner: Breslau.

Hirsch, E. (2002). Quantifier variance and realism. In E. Sosa \& E. Villanueva (Eds.), Realism and relativism. Philosophical issues 12 (pp. 51-73). Oxford: Blackwell.

Hirsch, E. (2005). Physical-object ontology, verbal disputes, and common sense. Philosophy and Phenomenological Research, 70(1), 67-97.

Hirsch, E. (2009). Ontology and alternative languages. In D. Chalmers, D. Manley, \& R. Wasserman (Eds.), Metaphysics (pp. 231-258). Oxford University Press: Oxford.

Lewis, D. (1973). Counterfactuals. Oxford: Blackwell.

Lewis, D. (1986). On the plurality of worlds. Oxford: Basil Blackwell.

Musgrave, A. (1989). NOA's ark-Fine for realism. The Philosophical Quarterly, 39(157), 383-398.

Quine, W. v. O. (1951). Two dogmas of empiricism. Philosophical Review, 60(1), 20-43.

Quine, W. v. O. (1960). Word and object. Cambridge, MA: MIT Press.

Sellars, W. (1956). Empiricism and the philosophy of mind. In W. Sellars, R. Rorty, \& R. Brandom (Eds.), Science, perception and reality (1963) (pp. 127-196). Atascadero: Ridgeview Publishing Company.

Strawson, P. F. (1950). Truth. Proceedings of the Aristotelian Society, supplementary volume 24, (pp. 129-56).

Thomasson, A. L. (2007). Ordinary objects. Oxford: Oxford University Press.

Thomasson, A. L. (2008). Existence questions. Philosophical Studies, 141, 63-78.

Thomasson, A. L. (2009a). Answerable and unanswerable question. In D. Chalmers, et al. (Eds.), Metametaphysics. Oxford: Oxford University Press.

Thomasson, A. L. (2009b). The easy approach to ontology. Axiomathes, 19, 1-15.

Thomasson, A. L. (2013). Fictionalism versus deflationism. Mind, 122(488), 1023-1051.

Thomasson, A. L. (2015). Ontology made easy. Oxford: Oxford University Press.

Thomasson, A. L. (2016). Carnap and the prospects for easy ontology. In S. Blatti \& S. LaPointe (Eds.), Ontology after carnap (pp. 122-144). Oxford: Oxford University Press.

Thomasson, A. L. (forthcoming). Easy ontology and its consequences. In G. Ostertag (Ed.), Meanings and other things: Essays on Stephen Schiffer. Cambridge MA: MIT Press.

Trueman, R. (2014). A dilemma for neo-fregeanism. Philosophia Mathematica, 22(3), 361-379.

van Inwagen, P. (1990). Material beings. London: Cornell University Press.

\footnotetext{
49 So, by the back door, this brings me to my position in Button (2013, pp. 1, 161-178, 193-196, 217-221): there is no master argument against metaphysics; we must instead treat metaphysical debates case-by-case. This paper has benefitted from conversations with many people, most especially Amie Thomasson and Rob Trueman. Thanks also to two anonymous referees for this journal, Neil Barton, Richard Gaskin, Peter Hulme, Jack Marley-Payne, Hugh Mellor, Kyle Mitchell, Huw Price, Carlo Rossi, Mark Sainsbury, Teru Thomas, Nathan Wildman, Sam Wolfe, and audiences at Birkbeck, Cambridge, Oxford and Liverpool.
} 
van Inwagen, P. (2009). The new anti-metaphysicians. Proceedings and Addresses of the American Philosophical Association, 83(2), 45-61.

Wittgenstein, L. (1931-4). Philosophical grammar. Blackwell: Oxford.

Wittgenstein, L. (1953). Philosophical investigations (E. Anscombe, Trans.). Chichester: Blackwell. 